\title{
Perfil citológico vaginal de ovelhas durante protocolo de indução e sincronização do estro
}

Brenda Oliveira Silveira, Andressa Silveira Gonçalves, Luiza Rodegheri Jacondino, Beatriz Riet Correa Rivero, Eneder Rosana Oberst, Raquel Fraga e Silva Raimondo*

Núcleo RuminAção, ensino, pesquisa e extensão em ruminantes, Faculdade de Veterinária, Universidade Federal do Rio Grande do Sul (UFRGS), Porto Alegre, RS, Brasil

*Autor correspondente

e-mail: rfraimondo@gmail.com

\section{Resumo}

O método indireto mais comum utilizado para o estudo do ciclo estral é a citologia vaginal esfoliativa, que possibilita a observação dos tipos celulares vaginais que coincidem com a fase hormonal correspondente. De acordo com a literatura compulsada, em caprinos foi observada variação no padrão citológico celular em fêmeas induzidas ao estro com hormônios, em relação as que apresentaram estros naturais. 0 objetivo do estudo foi avaliar o perfil citológico vaginal de ovelhas submetidas a protocolo de indução e sincronização do estro. 0 experimento foi realizado no mês de novembro, fase de anestro em ovinos, utilizando-se 11 ovelhas mestiças da raça Corriedale. Em fase aleatória do ciclo estral (dia 0), as ovelhas receberam por sete dias um dispositivo intravaginal (PrimerPR ${ }^{\circledR}$, Tecnopec, Brasil) impregnado com 0,36g de progesterona. No dia da retirada do dispositivo receberam 0,0375mg de D-Cloprostenol (Prolise ${ }^{\circledR}$, Tecnopec, Brasil) e 10mg de Foltropina de hipófise suína (Folltropin ${ }^{\circledR}$, Tecnopec, Brasil) por via intramuscular. Esfregaços vaginais foram realizados nos dias -1, -3, 0 (colocação do dispositivo), 3 , 5, 7 (retirada do dispositivo), 8, 9 (provável estro), 10 e 21 dias. Para realização dos esfregaços utilizou-se de swab, que foi introduzido na comissura vulvar até o canal vaginal e movido em todas as direções, permitindo a coleta das células epiteliais vaginais. Estas células foram distendidas em lâmina de vidro, fixadas em álcool a 95\%, em seguida coradas pelo método panótico rápido e observadas ao microscópio óptico de luz com aumentos de 10x e 40x. Foram contadas 100 células por lâmina, e a classificadas pelas características morfológicas e tintoriais das células epiteliais. Os tipos celulares do epitélio vaginal observados foram classificados em quatro tipos de células: basal, parabasal, intermediárias e superficiais anucleadas. Notou-se que ao longo de todo período de avaliação ocorreu o predomínio de células intermediárias. No dia 9 (provável estro) era esperada uma maior frequência de células superficiais anucleadas, o que não ocorreu. No período de estro, em decorrência da influência estrogênica sobre o epitélio vaginal, ocorre uma intensa descamação e o aparecimento de 
células de queratinizadas, com contornos citoplasmático retos e núcleos picnóticos e de células superficiais anucleadas. A menor observação destes tipos celulares no dia do provável aparecimento de estro indica que houve reduzida ação do estrógeno circulante e que o protocolo não foi efetivo em induzir manifestações de estro na citologia vaginal, como as referidas em ciclos naturais durante a temporada reprodutiva. 